\title{
Analysis of cutaneous allergic reactions in clinical trials of eslicarbazepine acetate
}

\author{
Joanne Rogin ${ }^{1}$ (D) | Trevor Resnick ${ }^{2}$ | Laura Strom ${ }^{3}$ | Elinor Ben-Menachem ${ }^{4}$ | \\ Silvia Kochen ${ }^{5}$ | David Blum ${ }^{6}$ | Helena Gama ${ }^{7}$ | Patrício Soares-da-Silva ${ }^{7,8}$ | Yan Li ${ }^{6}$ | \\ Todd Grinnell ${ }^{6}$ \\ ${ }^{1}$ Midwest Center for Seizure Disorders, Minneapolis Clinic of Neurology, Golden Valley, MN, USA \\ ${ }^{2}$ Department of Neurology, Nicklaus Children's Hospital, Florida International University, Miami, FL, USA \\ ${ }^{3}$ Department of Neurology, University of Colorado Denver Health Sciences, Aurora, CO, USA \\ ${ }^{4}$ Sahlgrenska Academy Institute of Neuroscience and Physiology, Goteborg, Sweden \\ ${ }^{5}$ Neurosciences and Complex Systems Unit (ENyS), Epilepsy Section, CONICET, Hospital El Cruce "N. Kirchner", University National A. Jauretche (UNAJ), \\ University Buenos Aires, Buenos Aires, Argentina \\ ${ }^{6}$ Sunovion Pharmaceuticals Inc., Marlborough, MA, USA \\ ${ }^{7}$ BIAL - Portela \& C-a - S.A., S. Mamede do Coronado, Portugal \\ ${ }^{8}$ MedInUP - Center for Drug Discovery and Innovative Medicines, University of Porto, Porto, Portugal
}

Correspondence

David Blum, Sunovion Pharmaceuticals Inc., 84 Waterford Drive, Marlborough, MA 01752, USA.

Email: davideblum@gmail.com

Funding information

Studies 301, 302, 208, 304, and 305 were funded by BIAL. Study 304 , and the data analyses were funded by Sunovion Pharmaceuticals Inc.
Objectives: To evaluate cutaneous allergic reactions in clinical trials of adjunctive eslicarbazepine acetate (ESL) for focal seizures.

Materials and methods: Data were analyzed from three phase III randomized, double-blind, placebo-controlled studies of adjunctive ESL in adults (placebo, $n=426$; ESL, $\mathrm{n}=1021$ ) and two randomized, double-blind, placebo-controlled studies (and open-label extensions [OLEs]) of adjunctive ESL in children aged 4-17 years (placebo, $\mathrm{n}=160 ; \mathrm{ESL}, \mathrm{n}=202$; OLE, $\mathrm{n}=337$ ).

Results: Adult studies: Rash (ESL 1.9\%, placebo 0.9\%) and pruritus (ESL 1.2\%, placebo $0.9 \%$ ) were the most frequent rash-related treatment-emergent adverse events (TEAEs). Most rash-related TEAEs were mild or moderate in severity. Incidence of rash increased with increasing ESL dose, but was not higher for patients who initiated treatment with higher ESL doses. Pediatric studies: Allergic dermatitis (ESL 3.0\%, placebo 0 ) and rash (controlled studies: ESL 1.0\%, placebo 1.3\%; OLE periods: ESL $\leq 1.2 \%$ ) were the most frequent rash-related TEAEs. There was one case of DRESS in the ESL group. Most rash-related TEAEs were mild or moderate in severity and judged as not related to treatment with ESL.

Conclusions: Serious skin rashes were rare during adult and pediatric clinical trials of ESL. Although the incidence of rash with ESL was low, it is important for patients/ caregivers to be made aware of the potential signs and symptoms associated with serious skin rashes. 
KEYWORDS

adjunctive, allergic reactions, epilepsy, eslicarbazepine acetate, focal seizures, pediatric, rash, safety

\section{1 | INTRODUCTION}

Clinicians recognize that allergic reactions, including serious skin rashes such as Stevens-Johnson syndrome (SJS), drug reaction with eosinophilia and systemic symptoms (DRESS), and toxic epidermal necrolysis (TEN), may occur with antiepileptic drug (AED) use $\mathrm{e}^{1-3}$ and that certain hypersensitivity reactions may be more likely to occur in children than adults. ${ }^{4}$

Eslicarbazepine acetate (ESL) is a once-daily, oral AED for the treatment of focal (partial-onset) seizures in patients aged 4 years and older in the USA. ${ }^{5}$ Double-blind, fixed-duration clinical trials of adjunctive ESL have demonstrated that ESL is an effective and well-tolerated treatment for focal seizures in both adults and children. ${ }^{6-11} \mathrm{ESL}$ is a dibenzazepine carboxamide derivative. Relatively high rates of rash have previously been observed with phenytoin and lamotrigine (LTG), and other dibenzazepine carboxamides such as carbamazepine (CBZ) and oxcarbazepine (OXC), ${ }^{1,2,12-19}$ and so it is relevant to examine to what extent allergic reactions also occur with ESL, and whether there may be any identifiable risk factors.

In the current analysis, we report incidences of cutaneous allergic reactions and serious idiosyncratic skin rashes such as SJS, DRESS, and TEN in clinical trials of adjunctive ESL for focal seizures in adults and children.

\section{2 | MATERIALS AND METHODS}

\section{1 | Study design}

The studies were designed, conducted, and monitored in accordance with the principles of the Declaration of Helsinki, the International Conference on Harmonisation guidelines, and relevant national, state, and local laws. The study protocols were approved by the relevant independent ethics committees/institutional review boards, and all patients provided written informed consent.

\subsection{1 | Adult studies}

Patient data from three phase III randomized, double-blind, placebo-controlled studies of adjunctive ESL (BIA-2093-301 Part 1/-302 Part 1/-304 Part 1; NCT00957684, NCT00957047, and NCT00988429, respectively) were pooled and analyzed. A similar study, BIA-2093-303, was also conducted, but was excluded from this analysis due to non-compliance with Good Clinical Practice. Patients were aged $\geq 16$ or $\geq 18$ years, with focal seizures not adequately controlled with 1-3 AEDs. After completing an 8-week baseline period, patients were randomized equally to receive oral placebo, ESL 400 mg (Studies 301 and 302 only), 800 mg, or $1200 \mathrm{mg}$ once-daily for a 2-week titration period, followed by a 12-week fixed-dose maintenance period. Patients continued to receive stable doses of baseline concomitant AEDs. Full patient eligibility criteria and study details have been previously reported. ${ }^{6-8}$ In Study 304 (but not Study 301 or 302), a positive human leukocyte antigen (HLA)-B*1502 test (in patients of Asian ancestry) was an exclusion criterion.

\subsection{2 | Pediatric studies}

Pooled safety data from patients aged 4-17 years in Studies BIA2093-208 and BIA-2093-305 (NCT01527513 and NCT00988156, respectively) were analyzed to support demonstration of safety as part of a data package submitted to the US Food and Drug Administration (FDA) to request extrapolation of efficacy data from adults to pediatric patients aged 4-17 years with focal seizures. Studies 208 and 305 were randomized, double-blind, placebo-controlled studies of adjunctive ESL in children with focal seizures refractory to 1-2 AEDs. HLA-related exclusion criteria were not used.

Study 208-Part 1 was a 12-week, phase II study in patients aged 6-16 years. ESL was titrated to the target dose ( $30 \mathrm{mg} / \mathrm{kg} /$ day) over 4 weeks ( $10 \mathrm{mg} / \mathrm{kg} /$ day for 2 weeks, $20 \mathrm{mg} / \mathrm{kg} /$ day for 2 weeks). If patients tolerated $20 \mathrm{mg} / \mathrm{kg} /$ day, the dose was increased to $30 \mathrm{mg} /$ $\mathrm{kg}$ /day (maximum dose: $1200 \mathrm{mg} /$ day) for the 8-week maintenance period. Dose reduction was allowed once, during either the titration period (from 20 to $10 \mathrm{mg} / \mathrm{kg} /$ day) or the maintenance period (from 30 to $20 \mathrm{mg} / \mathrm{kg} /$ day). ${ }^{11}$

Study 305-Part 1 was an 18-week, phase III study in patients aged 2-18 years. ESL was titrated to the target dose $(20 \mathrm{mg} / \mathrm{kg} /$ day $)$ over 6 weeks ( $10 \mathrm{mg} / \mathrm{kg} /$ day for 2 weeks, $20 \mathrm{mg} / \mathrm{kg} /$ day for 4 weeks). If tolerability and therapeutic response were considered acceptable after the titration period, patients continued to receive $20 \mathrm{mg} / \mathrm{kg} /$ day during the 12-week maintenance period. If tolerability was considered acceptable but therapeutic response was insufficient, the dose was increased to $30 \mathrm{mg} / \mathrm{kg} /$ day (maximum dose: $1200 \mathrm{mg} / \mathrm{day}$ ) for the 12-week maintenance period. Dose reduction was allowed once, during either the titration period (from 20 to $10 \mathrm{mg} / \mathrm{kg} /$ day) or the maintenance period (from 30 to $20 \mathrm{mg} / \mathrm{kg} /$ day or 20 to $10 \mathrm{mg}$ / $\mathrm{kg} /$ day). ${ }^{10}$

Patients could continue into a 1-year uncontrolled, open-label extension (OLE) in both studies (Part 2). Patients could subsequently continue into a 2-year OLE (Part 3) in Study 208, or two 
additional 1-year OLEs, followed by a 2-year OLE in Study 305 (Parts 3-5).

\subsection{Assessments and data analysis}

This post hoc, exploratory analysis used the safety populations of the adult and pediatric controlled studies of adjunctive ESL. The safety populations comprised all patients who received at least one dose of study medication (placebo or ESL) in Study 301, 302, 304, 208, or 305. The pediatric safety population included patients aged 4-17 years; in Part 1 of Study 305, all investigational medicinal recall patients were excluded (ESL was withdrawn from 41 patients in Stratum 1 [2-6-year age group], due to stability issues with the oral suspension used).

Demographic and clinical characteristics examined at baseline included age, gender, and baseline AED use.

Rash-related treatment-emergent adverse events (TEAEs) were classified based on verbatim descriptions of events provided by investigators and included those identified by the standardized Medical Dictionary for Regulatory Activities (MedDRA) query of "severe cutaneous adverse reactions" and those including any of the following text: "blister*," "prurit*," "rash," "exanthema*," "erythema," "rosacea," "urticaria," or "dermatitis" (* represents any subsequent text in the word).

In addition, potential cases of DRESS that met RegiSCAR (European Registry of Severe Cutaneous Adverse Reactions [SCAR] to Drugs and Collection of Biological Samples) criteria were identified by database searches for related signs and symptoms. The presence of at least three of the following was taken to indicate DRESS: fever, acute rash, lymphadenopathy, internal organ involvement, and abnormal blood cell counts (low or high lymphocytes, high eosinophils, low platelets). Hospitalization was not included in the evaluation of potential DRESS.

The safety database for the adult studies was also queried for the presence of cutaneous allergic reaction events of particular medical interest, as identified by physician review.

\section{3 | RESULTS}

\section{1 | Demographic and patient characteristics}

\subsection{1 | Adult studies}

In Part 1 of the three phase III clinical trials in adults, 426 patients received placebo and 1021 received ESL (400 mg, $n=196 ; 800$ mg, $n=415 ; 1200 \mathrm{mg}, \mathrm{n}=410$ ). Median ages were similar across treatment groups (37-38 years), and there were similar proportions of male and female patients ( $45 \%-52 \%$ males). Median exposure to ESL was 98 days, and $72 \%$ of patients were taking $\geq 2$ concomitant AEDs. The most common baseline AEDs were CBZ (placebo, 46\%; ESL, 51\%), LTG (placebo, 25\%; ESL, 24\%), valproic acid (placebo, $22 \%$; ESL, 21\%), and levetiracetam (LEV; placebo, 21\%; ESL, 17\%).

\subsection{2 | Pediatric studies}

In the two clinical trials in children, 160 patients received placebo and 202 received ESL; 337 patients entered the OLEs. Median ages were similar (10 and 11 years, respectively), and there were similar proportions of male and female patients (53\% and 50\%) in the placebo and ESL groups. Most patients were in the 12-17-year (placebo, 41\%; ESL, 47\%) or 7-11-year (placebo, 41\%; ESL, 42\%) age categories, and in the $>38 \mathrm{~kg}$ body weight category (placebo, 47\%; ESL, 55\%). Median exposure to ESL was 139 days, and 73\% of patients overall were taking $\geq 2$ concomitant AEDs. The most common baseline AEDs were valproic acid (placebo, 53\%; ESL, 49\%), CBZ (placebo, 26\%; ESL, 30\%), LTG (placebo, 28\%; ESL, 25\%), topiramate (placebo, 24\%; ESL, 25\%), and LEV (placebo, 18\%; ESL, 19\%).

\section{2 | Allergic reaction adverse events}

\subsection{1 | Adult studies}

Rash and pruritus were the most frequently reported rash-related TEAEs, with numerically higher incidences with ESL vs placebo (rash: ESL 1.9\%, placebo 0.9\%; pruritus: ESL 1.2\%, placebo $0.9 \%$ ) (Table 1). Eye pruritus, mouth ulceration, and dermatitis were also reported in $>1$ patient taking ESL. Most rash-related TEAEs in the ESL treatment groups were mild or moderate in severity. The relationships of rash-related TEAEs to treatment with ESL are reported in Table 1; one report of rash and one report of drug eruption were judged to be definitely related to treatment with ESL. In Study 304, the median time between treatment initiation and onset of rash was 14 days. In Studies 301 and 302, the highest incidences of skin and subcutaneous tissue disorders were during Days 1-13 of treatment with ESL (Study 301: 1.7\%, Study 302: $2.0 \%$ ), with incidences tapering off throughout the duration of the studies. The majority of rash-related TEAEs did not result in discontinuation of ESL (Table 1). The incidence of the specific investigator-reported TEAE term "rash" was higher in patients who received higher target doses of ESL (placebo 0.9\%; ESL $400 \mathrm{mg}$ 0.5\%; ESL 800 mg 1.2\%; ESL 1200 mg 3.2\%; Figure 1). The incidence of "rash" was not higher for patients who initiated dosing with ESL 800 mg vs ESL 400 mg. For example, in patients with a target maintenance dose of ESL $1200 \mathrm{mg}$, the incidence of "rash" was $4.9 \%$ in those who initiated dosing at $400 \mathrm{mg}$ vs $2.6 \%$ in those who initiated dosing at $800 \mathrm{mg}$. The median time to onset of "rash" in patients taking ESL ( $\mathrm{n}=19$ ) was 14 days, with $25 \%$ of "rash" events starting within 9 days (ie, during the titration period) and $75 \%$ starting within 43 days. The median time to onset of "rash" in the placebo group was 39 days (interquartile range: 29-60 days; $n=4)$, longer than in the ESL treatment groups.

There were no investigator-reported cases of DRESS, SJS, or TEN during the phase III trials of adjunctive ESL in adults. However, additional analysis of the database identified that two patients taking ESL (0.2\%) had combinations of TEAEs that potentially met 
TAB LE 1 Rash-related TEAEs ${ }^{\mathrm{a}}$ in controlled clinical trials of ESL in adults

\begin{tabular}{|c|c|c|c|c|}
\hline n (\%) & Placebo $(n=426)$ & $\operatorname{ESL}(n=1021)$ & $\begin{array}{l}\text { Relationship }{ }^{\mathrm{b}} \text { of rash-related TEAE } \\
\text { to treatment with } \mathrm{ESL}\end{array}$ & $\begin{array}{l}\text { ESL discontinued due to } \\
\text { rash-related TEAE }(n=1021)\end{array}$ \\
\hline Rash & $4(0.9)$ & 19 (1.9) & $\begin{array}{l}\text { Potentially related: } 14 \text { (1.4) } \\
\text { Not related: } 5(0.5)\end{array}$ & $7(0.7)$ \\
\hline Pruritus & $4(0.9)$ & $12(1.2)$ & $\begin{array}{l}\text { Potentially related: } 7(0.7) \\
\text { Not related: } 5(0.5)\end{array}$ & $3(0.3)$ \\
\hline Contact dermatitis & $1(0.2)$ & $3(0.3)$ & $\begin{array}{l}\text { Potentially related: } 1(<0.1) \\
\text { Not related: } 2(0.2)\end{array}$ & 0 \\
\hline Eye pruritus & 0 & $3(0.3)$ & $\begin{array}{l}\text { Potentially related: } 2(0.2) \\
\text { Not related: } 1(<0.1)\end{array}$ & 0 \\
\hline Mouth ulceration & 0 & $3(0.3)$ & $\begin{array}{l}\text { Potentially related: } 1(<0.1) \\
\text { Not related: } 2(0.2)\end{array}$ & 0 \\
\hline Dermatitis & 0 & $2(0.2)$ & Not related: $2(0.2)$ & 0 \\
\hline Drug eruption & 0 & $1(<0.1)$ & Potentially related & $1(<0.1)$ \\
\hline Exfoliative rash & 0 & $1(<0.1)$ & Potentially related & 0 \\
\hline Papular rash & $1(0.2)$ & $1(<0.1)$ & Potentially related & 0 \\
\hline Pruritic rash & 0 & $1(<0.1)$ & Not related & 0 \\
\hline Vesicular rash & $1(0.2)$ & $1(<0.1)$ & Potentially related & 0 \\
\hline
\end{tabular}

Abbreviations: ESL, eslicarbazepine acetate; TEAE, treatment-emergent adverse event.

${ }^{\text {a }}$ Reported in $\geq 1$ patient taking ESL.

'The TEAE was considered "potentially related" to treatment if the investigator judged the relationship to treatment to be "possible," "probable,"

"definite," "unknown" or "missing." The TEAE was considered "not related" to treatment if the investigator judged the relationship to treatment to be "unlikely" or "not related."

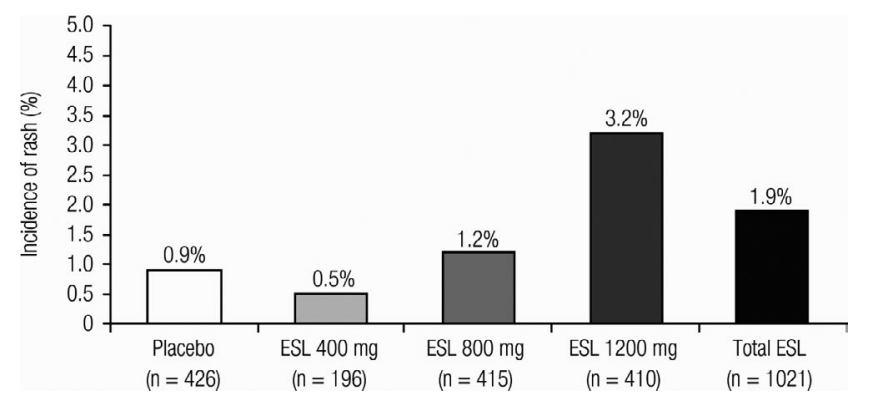

FIGURE 1 Incidence of "rash" in clinical trials of ESL in adults, according to target dose. ESL, eslicarbazepine acetate

RegiSCAR Criteria for DRESS syndrome (Table 2). The first potential case of DRESS occurred in a 36-year-old Caucasian female taking ESL 1200 mg in Study 301. Severe rash occurred after 13 days of treatment with ESL; increased aspartate aminotransferase (AST)/lactate dehydrogenase (LDH)/gamma-glutamyl transferase (GGT), leukopenia, and fever were also reported. The patient was hospitalized, and the AE classified as serious; she recovered 5 days after discontinuation of ESL. The second potential case of DRESS occurred in a 44-year-old Caucasian female taking ESL $400 \mathrm{mg}$ in Study 301. Moderate rash occurred after 92 days of treatment with ESL; mildly elevated alanine aminotransferase (ALT)/AST, fever, and low platelet count were also reported. The patient was not hospitalized, the AE was not classified as serious, and the patient did not discontinue treatment with ESL due to rash.

\subsection{2 | Pediatric studies}

Allergic dermatitis and rash were the most frequently reported rash-related TEAEs during the controlled studies; the incidence of allergic dermatitis was numerically higher with ESL vs placebo (ESL, 3.0\%; placebo, 0), whereas the incidence of rash was comparable between groups (ESL, 1.0\%; placebo, 1.3\%) (Table 3). DRESS and pruritus were also reported in the ESL group, in one patient each. Most rash-related TEAEs with ESL were mild or moderate in severity and judged not to be related to treatment with ESL (Table 3); two reports of allergic dermatitis, one report of rash, and the case of DRESS were judged to be related to treatment with ESL. Single cases of DRESS and allergic dermatitis occurred within a week, and single cases of allergic dermatitis and rash occurred during the second week after initiating treatment with ESL (Table 3). Two further cases of allergic dermatitis occurred within a month of initiating treatment with ESL, with all other rash-related TEAEs occurring after at least a month of treatment (Table 3). The majority of rash-related TEAEs did not lead to discontinuation of ESL (Table 3). Rash was the most frequently reported rash-related 
TAB LE 2 Cases of DRESS with ESL during clinical trials in adults $(n=1021)$ and children $(n=202)$

\begin{tabular}{|c|c|c|c|}
\hline Case & $\begin{array}{l}\text { Presentation of DRESS and } \\
\text { effects of discontinuing } \\
\text { treatment with ESL }\end{array}$ & $\begin{array}{l}\text { Duration of exposure to ESL } \\
\text { and medical history (duration } \\
\text { prior to DRESS) }\end{array}$ & Concomitant medications \\
\hline $\begin{array}{l}\text { Potential DRESS with ESL } \\
400 \mathrm{mg} \\
44 \text {-year-old Caucasian female } \\
\text { (Study 301) }\end{array}$ & $\begin{array}{l}\text { Rash (moderate) } \\
\text { Mildly elevated ALT/AST } \\
\text { Fever } \\
\text { Low platelet count } \\
\text { The patient was not } \\
\text { hospitalized and the AE was } \\
\text { not classified as serious } \\
\text { The patient did not } \\
\text { discontinue treatment with } \\
\text { ESL due to rash }\end{array}$ & $\begin{array}{l}\text { Exposure to ESL: } 92 \mathrm{~d} \\
\text { Intracranial hemangioma } \\
\text { (arteriovenous hemangioma } \\
\text { intracranial-neurosurgical } \\
\text { operation; } ~ 6 \text { y) } \\
\text { Mania (7 mo) }\end{array}$ & $\begin{array}{l}\text { Clonazepam } \\
\text { Sodium valproate } \\
\text { Spironolactone } \\
\text { Furosemide } \\
\text { Risperidone } \\
\text { Initiated during study: diazepam, tramadol } \\
\text { hydrochloride, mannitol, valproic acid, } \\
\text { clonazepam, furosemide, electrolyte } \\
\text { solution, calcium }\end{array}$ \\
\hline $\begin{array}{l}\text { DRESS with ESL } 200 \mathrm{mg} \\
\text { 5-year-old Caucasian female } \\
\text { (Study 305) }\end{array}$ & $\begin{array}{l}\text { Increased C-reactive protein } \\
\text { Dysphagia } \\
\text { Macular skin changes on face, } \\
\text { ear, neck, chest and arms } \\
\text { Edema } \\
\text { Pyrexia } \\
\text { Increased ALT/AST } \\
\text { The patient was hospitalized } \\
\text { and the AE was classified as } \\
\text { serious } \\
\text { The patient recovered } 32 \mathrm{~d} \\
\text { after discontinuation of ESL }\end{array}$ & $\begin{array}{l}\text { Exposure to ESL: } 6 \mathrm{~d} \\
\text { Epilepsy ( } 5 \text { y } 4 \mathrm{mo}) \\
\text { Cardiac murmur }(5 \text { y } 1 \mathrm{~m}) \\
\text { Dermoid cyst ( } 3 \text { y } 7 \mathrm{mo})\end{array}$ & $\begin{array}{l}\text { Valproic acid } \\
\text { Clobazam } \\
\text { Sultiame }\end{array}$ \\
\hline
\end{tabular}

Abbreviations: AE, adverse event; ALT, alanine aminotransferase; AST, aspartate aminotransferase; d, days; DRESS, Drug Reaction with Eosinophilia and Systemic Symptoms; ESL, eslicarbazepine acetate; GGT, gamma-glutamyl transferase; LDH, lactate dehydrogenase; mo, months; y, years.

TEAE during the OLE periods (ESL, 1.2\%); urticaria, vesicular rash, allergic dermatitis, and hypersensitivity (moderate severity) were also reported (Table 3). Again, most of the rash-related TEAEs reported during the OLE periods were judged not to be related to treatment with ESL (Table 3). Overall, one of the rash-related TEAEs reported during the controlled studies/OLEs was serious and resulted in discontinuation (DRESS; 0.5\%). The case of DRESS occurred in a 5-year-old Caucasian female taking ESL $200 \mathrm{mg}$ in Study 305, after 6 days of treatment with ESL. Increased C-reactive protein, dysphagia, macular skin changes on the face, ear, neck, chest and arms, edema, pyrexia, and increased ALT/AST were reported. The patient was hospitalized, and the AE classified as serious; she recovered 32 days after discontinuation of ESL (Table 2). Three rash-related TEAEs reported during the controlled studies/OLEs were serious but did not result in discontinuation (vesicular rash and two cases of urticaria); the case of vesicular rash and one case of urticaria were judged by the investigator as not related to treatment with ESL, and the other case of urticaria was judged as unlikely related to ESL. Four rash-related TEAEs (rash and allergic dermatitis [ $\mathrm{n}=2$ each]) were non-serious but led to discontinuation; the remaining rash-related TEAEs were judged as non-serious and did not lead to discontinuation. There were no cases of SJS or TEN.

In the controlled studies, median time to onset of the specific investigator-reported TEAE term "rash" in patients taking ESL $(n=4)$ was 44 days (interquartile range: 8-81 days). This was shorter than the median time to onset of rash in the placebo group (67 days [interquartile range: $22-72$ days]; $n=5$ ).

\section{4 | DISCUSSION}

This analysis found that idiosyncratic allergic reactions occurred infrequently in patients taking ESL, with the majority of events being mild or moderate in severity. There were no instances of SJS or TEN in three adult and two pediatric controlled clinical trials ( $n=1223$ taking ESL), but one investigator-reported case of DRESS (in Study 305). 
TABLE 3 Rash-related TEAEs in clinical trials of ESL in children

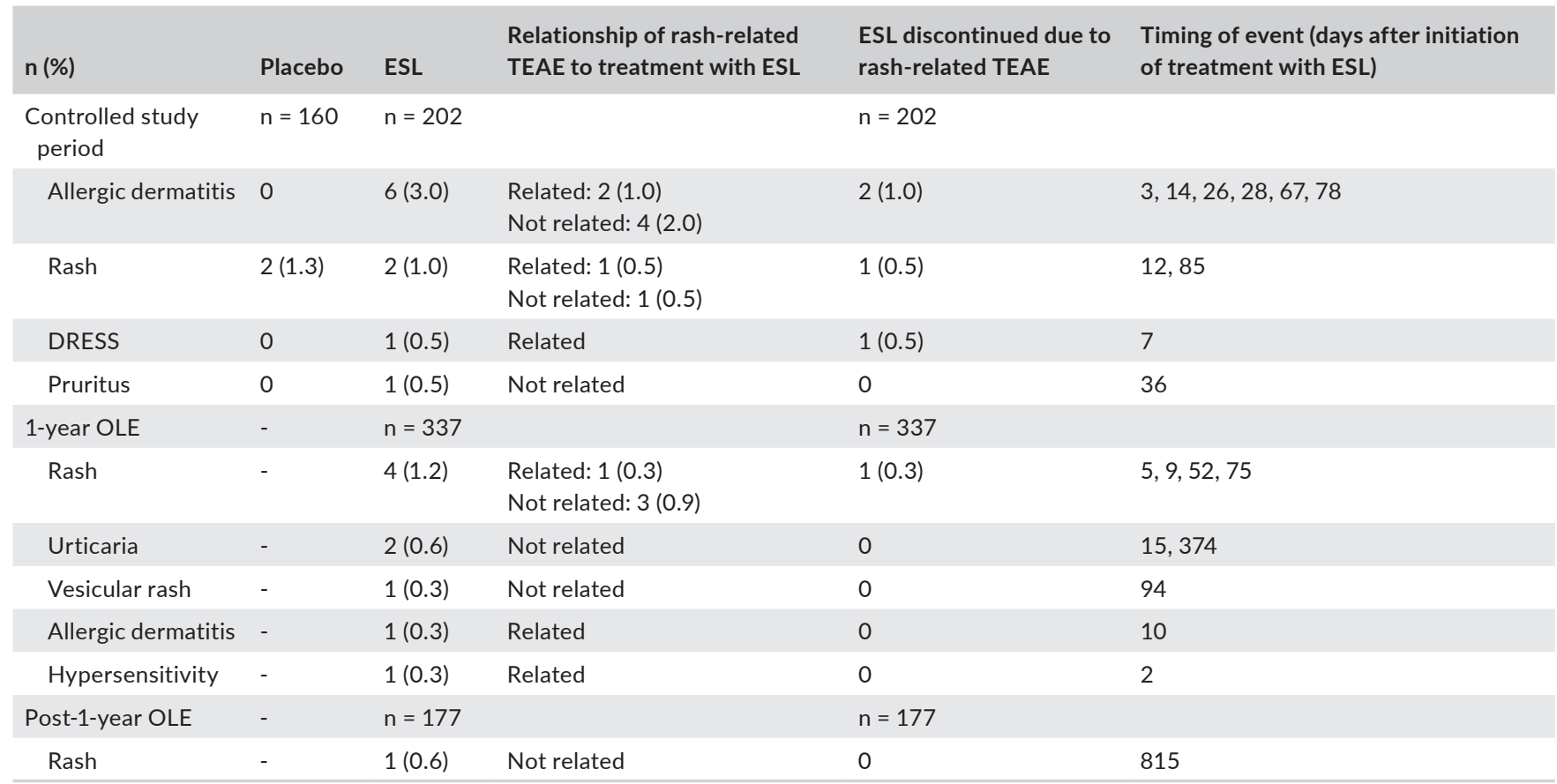

Abbreviations: DRESS, drug reaction with eosinophilia and systemic symptoms; ESL, eslicarbazepine acetate; OLE, open-label extension; TEAE, treatment-emergent adverse event.

Two cases of potential DRESS were identified (via database analysis) in the adult studies. Database analysis enabled the reliable identification of any serious skin rashes potentially related to the use of ESL. Across the adult and pediatric studies, there were no clear similarities between the three subjects that experienced serious skin rashes, and so risk factors for these events could not be identified from this analysis. If a patient presents with signs or symptoms of DRESS (fever, rash, and/or lymphadenopathy, in association with organ system involvement such as hepatitis, nephritis, hematological abnormalities, myocarditis, or myositis [sometimes resembling an acute viral infection], often with eosinophilia), they should be evaluated immediately and ESL should be discontinued; if an alternative etiology cannot be established, treatment with ESL should not be resumed. ${ }^{20}$

In the analysis conducted for this manuscript, all TEAEs potentially related to rash or hypersensitivity were identified. However, the majority of the hypersensitivity-related TEAEs in the adult studies were not related to rash, severe cutaneous reactions, or to ESL, and so were not included in this report. The most frequently reported $(\geq 0.5 \%$ of patients) non-rash-related hypersensitivity TEAEs with ESL in the adult studies were cough (1.1\%), decreased diastolic blood pressure $(0.9 \%)$, hypotension $(0.7 \%)$, decreased blood pressure $(0.6 \%)$, dyspnea $(0.6 \%)$, decreased systolic blood pressure (0.5\%), and chest discomfort (0.5\%).

In the adult studies, the two most frequently reported rash-related TEAEs, rash and pruritus, were more frequent in patients taking ESL than in those taking placebo ( $1.9 \%$ vs $0.9 \%$ and $1.2 \%$ vs $0.9 \%$, respectively). In addition, rash was more likely to occur with higher (vs lower) target doses of ESL, but not with higher initiation doses. In the pediatric studies, allergic dermatitis and rash were the most frequently reported rash-related TEAEs, with allergic dermatitis being reported more frequently in patients taking ESL (3.0\%) than in those taking placebo $(n=0)$. As the pediatric studies were flexibly dosed and all patients initiated treatment with the same ESL dose (10 mg/kg/day), the effects of ESL target and initiation doses on the incidence of rash could not be analyzed. Rash-related TEAEs were mainly mild-to-moderate in severity and judged not to be related to treatment with ESL, in both the adult and pediatric trials. If a patient develops a rash-related TEAE, an anaphylactic reaction, or angioedema, discontinuation of ESL treatment is recommended (unless the rash-related TEAE is clearly not drug-related). ${ }^{20}$

Allergic reaction TEAEs were not consistently analyzed during the adult clinical trial OLEs, and thus, only OL pediatric data are reported in the current analysis. Furthermore, an additional controlled study was conducted in adults with focal seizures, but was not included in this analysis (see Materials and Methods). In the additional study (Study BIA-2093-303), ${ }^{21} 165$ patients were exposed to ESL and there were no cases of serious or severe dermatologic or allergic reactions.

Although hypersensitivity reactions may be expected to occur more frequently in children than in adults, ${ }^{4}$ in this analysis of ESL, the rate of rash in the pediatric trials was similar to that in the adult trials; the relatively small number of pediatric patients may not have been adequate to demonstrate a difference. Additionally, differences between the adult and pediatric trials in terms of study designs (including more gradual dose titration in the pediatric studies), dosing paradigms, and data analyses do not allow for direct comparison.

Use of CBZ and OXC has previously been associated with relatively high rates of rash $\left(3 \%-19 \%{ }^{1,14-17,22}\right.$ and $3 \%-8 \%,{ }^{14,15,18,19}$ respectively). In addition, an analysis of AED-induced SCARs found that $C B Z$ was one of the major causative AEDs for this type of 
reaction. ${ }^{13}$ As ESL shares a similar chemical structure with both CBZ and OXC, the rate of rash with ESL was of particular interest. Although rates should not be compared between studies due to differences between study designs and analyses, it is noteworthy that in the current analysis, rash was infrequent with ESL (individual TEAEs occurred in $\leq 3 \%$ of patients), and that SCARs were rare.

The key finding of this analysis is that serious skin rashes were infrequent during adult and pediatric clinical trials of ESL. Although the incidence of rash was low in clinical trials of ESL, it is nonetheless important for patients/caregivers to be notified and made aware of the potential signs and symptoms associated with serious skin rashes.

\section{ACKNOWLEDGMENTS}

The authors would like to acknowledge the contributions of David Cantu, PhD, in drafting and revising the manuscript, and for his role in analyzing and interpreting the data reported herein. Medical writing support was provided by Mallory Gough, PhD, CMPP of FireKite, an Ashfield company, part of UDG Healthcare plc and was funded by Sunovion Pharmaceuticals Inc.).

\section{CONFLICT OF INTEREST}

Joanne Rogin has received honoraria from Eisai, Sunovion Pharmaceuticals Inc., and UCB; consultancy fees from Pfizer; and research support in the form of grants or funds from Eisai, GSK, Marinus, Pfizer, SK Life Science, Sunovion Pharmaceuticals Inc., and UCB. Trevor Resnick reports ownership of stocks/shares with Supernus and has received honoraria from Sunovion Pharmaceuticals Inc., Eisai, Supernus, and UCB. Laura Strom has no conflicts of interest to report. Elinor Ben-Menachem has received consultancy fees from Eisai, Sandoz, UCB, and GW Pharma; grants or funds from Eisai, UCB, GW Pharma, and SK Life Science; and is Chief Editor for Acta Neurologica Scandinavica (Wiley Press). Silvia Kochen reports employment with CONICET and has received grants or funds from Argentina Ministry of Science and Technology and Productive Innovation (MINCYT). David Blum reports consultancy for and previous employment with Sunovion Pharmaceuticals Inc., Yan Li and Todd Grinnell report employment with Sunovion Pharmaceuticals Inc. Helena Gama reports employment with BIAL. Patrício Soares-da-Silva reports employment with BIAL and is a member of the BIAL board of directors.

\section{DATA AVAILABILITY STATEMENT}

Sunovion Pharmaceuticals Inc. is part of a clinical trial data sharing consortium that facilitates access for qualified researchers to selected anonymized clinical trial data. For up-to-date information on data availability please visit: https://www.clinicalstudydatarequest. com/Study-Sponsors.aspx and click on Sunovion.

\section{ORCID}

Joanne Rogin (iD https://orcid.org/0000-0003-2510-2807

\section{REFERENCES}

1. Arif $H$, Buchsbaum R, Weintraub $D$, et al. Comparison and predictors of rash associated with 15 antiepileptic drugs. Neurology. 2007;68(20):1701-1709.
2. Harden CL. Therapeutic safety monitoring: what to look for and when to look for it. Epilepsia. 2000;41(Suppl 8):S37-44.

3. Walsh SA, Creamer D. Drug reaction with eosinophilia and systemic symptoms (DRESS): a clinical update and review of current thinking. Clin Exp Dermatol. 2011;36(1):6-11.

4. Hirsch LJ, Weintraub DB, Buchsbaum R, et al. Predictors of Lamotrigine-associated rash. Epilepsia. 2006;47(2):318-322.

5. Sunovion Pharmaceuticals Inc. APTIOM ${ }^{\circledR}$ (eslicarbazepine acetate) Prescribing Information. 2015; http://www.accessdata.fda.gov/drugs atfda_docs/label/2015/022416s001lbl.pdf. Accessed June 22, 2017.

6. Elger C, Halasz P, Maia J, Almeida L, Soares-da-Silva P, B. I. A. Investigators Study Group. Efficacy and safety of eslicarbazepine acetate as adjunctive treatment in adults with refractory partial-onset seizures: a randomized, double-blind, placebo-controlled, parallel-group phase III study. Epilepsia. 2009;50(3):454-463.

7. Ben-Menachem E, Gabbai AA, Hufnagel A, Maia J, Almeida L, Soares-da-Silva P. Eslicarbazepine acetate as adjunctive therapy in adult patients with partial epilepsy. Epilepsy Res. 2010;89(2-3):278-285.

8. Sperling MR, Abou-Khalil B, Harvey J, et al. Eslicarbazepine acetate as adjunctive therapy in patients with uncontrolled partial-onset seizures: results of a phase III, double-blind, randomized, placebo-controlled trial. Epilepsia. 2015;56(2):244-253.

9. Biton V, Rogin JB, Krauss G, et al. Adjunctive eslicarbazepine acetate: A pooled analysis of three phase III trials. Epilepsy Behav. 2017;72:127-134.

10. Rocha J, Moreira P, Pinto R, Soares-da-Silva P. A placebo-controlled trial of eslicarbazepine acetate add-on therapy for partial seizures in children. Presented at the World Congress of Neurology, Santiago, Chile; October 31-November 5 2015. Poster WFN15-1736.

11. Jozwiak S, Veggiotti P, Moreira J, Gama H, Rocha F, Soares-da-Silva P. Effects of adjunctive eslicarbazepine acetate on neurocognitive functioning in children with refractory focal-onset seizures. Epilepsy Behav. 2018;81:1-11.

12. Rosati A, De Masi S, Guerrini R. Antiepileptic drug treatment in children with epilepsy. CNS Drugs. 2015;29(10):847-863.

13. Yang CY, Dao RL, Lee TJ, et al. Severe cutaneous adverse reactions to antiepileptic drugs in Asians. Neurology. 2011;77(23):2025-2033.

14. Alvestad S, Lydersen S, Brodtkorb E. Rash from antiepileptic drugs: influence by gender, age, and learning disability. Epilepsia. 2007;48(7):1360-1365.

15. Donati F, Gobbi G, Campistol J, et al. The cognitive effects of oxcarbazepine versus carbamazepine or valproate in newly diagnosed children with partial seizures. Seizure. 2007;16(8):670-679.

16. Brodie MJ, Overstall PW, Giorgi L. Multicentre, double-blind, randomised comparison between lamotrigine and carbamazepine in elderly patients with newly diagnosed epilepsy. The UK Lamotrigine Elderly Study Group. Epilepsy Res. 1999;37(1):81-87.

17. Chadwick D. Safety and efficacy of vigabatrin and carbamazepine in newly diagnosed epilepsy: a multicentre randomised double-blind study. Vigabatrin European Monotherapy Study Group. Lancet. 1999;354(9172):13-19.

18. Qin J, Wang $Y$, Huang $X F$, et al. Oxcarbazepine oral suspension in young pediatric patients with partial seizures and/or generalized tonic-clonic seizures in routine clinical practice in China: a prospective observational study. World Journal of Pediatrics. 2018;14(3):280-289.

19. Bourgeois BF, D'Souza J. Long-term safety and tolerability of oxcarbazepine in children: a review of clinical experience. Epilepsy Behav. 2005;7(3):375-382.

20. Sunovion Pharmaceuticals Inc. Aptiom ${ }^{\circledR}$ (Eslicarbazepine Acetate), Full Prescribing Information, 2019. https://www.accessdata.fda. gov/drugsatfda_docs/label/2019/022416s011lbl.pdf. Accessed August, 2019. 
21. Gil-Nagel A, Lopes-Lima J, Almeida L, Maia J, Soares-da-Silva P. Efficacy and safety of 800 and $1200 \mathrm{mg}$ eslicarbazepine acetate as adjunctive treatment in adults with refractory partial-onset seizures. Acta Neurol Scand. 2009;120(5):281-287.

22. Hogan RE, Garnett WR, Thadani VM, Carbatrol Study G. Tolerability and effects on quality of life of twice-daily extended-release carbamazepine in adults with seizure disorders: an open-label, 12- to 36-

How to cite this article: Rogin J, Resnick T, Strom L, et al. Analysis of cutaneous allergic reactions in clinical trials of eslicarbazepine acetate. Acta Neurol Scand. 2020;00:1-8. https://doi.org/10.1111/ane.13218 